Rev. Bras. Saúde Prod. Anim., Salvador, v.17, n.4, p.729-743 out./dez., 2016 http://www.rbspa.ufba.br ISSN 15199940

\title{
Características da carcaça e qualidade da carne de cordeiros Pantaneiros alimentados com teores crescentes de glicerina bruta
}

\author{
Carcass traits and meat quality of Pantaneiro lambs fed with increasing levels of crude \\ glycerin
}

CUNHA, Camila Magalhães ${ }^{1}$; CORNÉLIO, Thatiane da Cunha²; FERNANDES, Alexandre Rodrigo Mendes ${ }^{3}$; SENO, Leonardo de Oliveira ${ }^{3}$; RICARDO, Hélio de Almeida $^{4 *}$; OSÓRIO, José Carlos da Silveira ${ }^{3}$; OSÓRIO, Maria Teresa Moreira ${ }^{3}$; ALVES, Luis Gustavo Castro ${ }^{1}$; OLIVEIRA, Emanuel Almeida ${ }^{5}$

\footnotetext{
${ }^{1}$ Universidade Estadual de Londrina, Centro de Ciências Agrárias, Programa de Pós-Graduação em Ciência Animal, Londrina, Paraná, Brasil.

${ }^{2}$ Universidade Federal da Grande Dourados, Faculdade de Ciências Agrárias, Programa de PósGraduação em Zootecnia, Dourados, Mato Grosso do Sul, Brasil.

${ }^{3}$ Universidade Federal da Grande Dourados, Faculdade de Ciências Agrárias, Dourados, Mato Grosso do Sul, Brasil.

${ }^{4}$ Universidade Estadual Paulista, Faculdade de Medicina Veterinária e Zootecnia, Departamento de Produção Animal, Botucatu, São Paulo, Brasil.

${ }^{5}$ Universidade Estadual Paulista, Faculdade de Ciências Agrárias e Veterinárias, Departamento de Zootecnia, Jaboticabal, São Paulo, Brasil.

*Endereço para correspondência: haricardo@gmail.com
}

\section{RESUMO}

Objetivou-se avaliar o efeito da inclusão de glicerina bruta (GB) em substituição ao milho, na dieta de cordeiros Pantaneiros confinados, sobre as características da carcaça e qualidade da paleta e do pernil. Foram utilizados 24 cordeiros machos, não castrados, em delineamento inteiramente casualizado, com quatro tratamentos $(0,2,5,5,0 \mathrm{e}$ $7,5 \%$ de GB em base da MS). Não houve efeito da inclusão de GB sobre os não componentes de carcaça. Houve efeito quadrático para peso de carcaça quente, com menor valor para $2,5 \%$ de GB. A composição regional e tecidual da carcaça não foi alterada pela substituição do milho pela GB. A composição tecidual da paleta e pernil e as características instrumentais da paleta não foram afetadas pelos teores de GB. Houve efeito quadrático para a intensidade de amarelo do pernil, com maior valor para $5,0 \%$ de GB. O teor de extrato etéreo da paleta apresentou efeito linear decrescente. Pode-se recomendar a utilização de $7,5 \%$ de GB, na matéria seca, em substituição ao milho, sem alteração das características da carcaça e qualidade da carne.

Palavras-chave: área de olho de lombo, confinamento, coproduto, glicerol, nutrição, ovinos

\section{SUMMARY}

The objective was to assess the effect of inclusion of crude glycerin (CG) replacing corn in the diet of feedlot Pantaneiro lambs on the non-carcass components, regional and tissue composition, and carcass traits. Were used 24 not castrated males, in a completely randomized design with four treatments $(0,2.5,5.0$ and $7.5 \%$ of CG on DM basis). There was no effect of GB inclusion on non-carcass components. There was a quadratic effect for hot carcass weight, with lower value to $2.5 \%$ of $\mathrm{CG}$. Regional and tissue composition of the carcass was not affected by the substitution of corn by CG. The tissue composition of shoulder and leg and instrumental traits of the shoulder were not affected by CG. There was a quadratic effect for the yellowness of the leg, with high value for $5.0 \%$ of GB. The ether extract content of shoulder showed decreased linear effect. The use of $7.5 \%$ of $\mathrm{CG}$, in dry matter, can be recommend to replace corn of feedlot diets, without changing carcass traits and meat quality.

Keywords: coproduct, feedlot, glycerol, loin eye area, nutrition, sheep 


\section{INTRODUÇ̃̃O}

A ovinocultura de corte está em desenvolvimento no país, sendo que alguns aspectos podem ser melhorados, buscando aumentar a produtividade deste segmento (ARAÚJO et al., 2014). Portanto, faz-se necessário o estudo da utilização de recursos genéticos adaptados as nossas condições de produção, aliados a sistemas de manejo alimentar com custo reduzido (MOURA NETO et al., 2014; RICARDO et al., 2015).

O grupo genético de ovinos denominados "pantaneiros", oriundos de muitos cruzamentos ao longo de anos, pode ser útil para desenvolvimento da cadeia produtiva local, uma vez que estes animais são altamente adaptados para as condições ambientais da região (VARGAS JUNIOR et al., 2011; CRISPIM et al., 2013). Adequações dos produtores desses ovinos ao sistema tecnológico de criação devem ser realizadas para obtenção de precocidade muscular e apropriada espessura de gordura das carcaças dos animais comercializados para torná-los mais atrativos (MORA et. al., 2015).

Quanto ao manejo alimentar a glicerina bruta é uma alternativa na dieta dos ovinos. A glicerina corresponde a cerca de $10 \%$ da massa total resultante do processo de produção do biodiesel (CHI et al., 2007). Porém, com a produção excessiva pelo aumento da demanda de biodiesel, a glicerina não tem sido totalmente absorvida pelas indústrias, sendo viabilizadas novas alternativas de utilização, como seu uso na alimentação animal.

No Brasil, o manejo nutricional de cordeiros confinados é muito semelhante ao praticado para bovinos (CAMILO et al., 2015). Millen et al. (2009) identificaram que o milho é a principal fonte de energia das dietas para bovinos.
Diante das oscilações do mercado de commodities e da influência do clima sobre as regiões produtoras, a substituição do milho pela glicerina bruta se torna uma opção para redução dos custos.

Existem estudos sobre o uso de glicerina bruta como os de Gunn et al. (2010a), Gunn et al. (2010b), Gomes et al. (2011) e Lage et al. (2014) que avaliaram a glicerina na dieta de cordeiros e seus efeitos sobre a digestibilidade, desempenho e características de carcaça. Porém, há uma grande variabilidade no tipo de glicerina e na porcentagem utilizada na dieta, além da quantidade de teor de glicerol e ácidos graxos.

Neste contexto, objetivou-se de avaliar as características quantitativas da carcaça, da paleta e do pernil de cordeiros pantaneiros terminados em confinamento com dietas com teores crescentes de glicerina bruta em substituição ao milho.

\section{MATERIAL E MÉTODOS}

O experimento foi conduzido no confinamento do Centro de Pesquisa de Ovinos (CPO) da Universidade Federal da Grande Dourados, localizada no município de Dourados-MS. Foram utilizados 24 cordeiros machos não castrados, com idade média de 90 dias e peso médio de $20,02 \pm 1,5 \mathrm{~kg}$, sendo estes animais pertencentes a um grupo de ovinos naturalizados do estado de Mato Grosso do Sul, denominados "Pantaneiros" (VARGAS JUNIOR et al., 2014).

Os animais foram alojados em baias individuais com $2 \mathrm{~m}$, providas de comedouro e bebedouro tipo nipple e dispostas em área coberta. A cama utilizada nas baias para a retenção de fezes e urina era de maravalha e trocada a cada quinze dias. Antes dos animais iniciarem o experimento os mesmos 
Rev. Bras. Saúde Prod. Anim., Salvador, v.17, n.4, p.729-743 out./dez., 2016 http://www.rbspa.ufba.br ISSN 15199940

foram numerados, pesados, desverminados (Ivermectina 1\%) e submetidos à adaptação (instalações e as dietas) por um período de 10 dias.

$\mathrm{O}$ experimento foi conduzido em um delineamento inteiramente casualizado, com quatro tratamentos e seis repetições. Os tratamentos testados foram o controle ( $0 \%$ de glicerina bruta) e três níveis de inclusão de glicerina bruta $(2,5,5,0 \mathrm{e}$ $7,5 \%$ de glicerina bruta) em substituição ao milho na matéria seca (MS) da dieta.

A glicerina bruta utilizada no experimento apresentou a seguinte composição: $39,3 \%$ de glicerol, $47,3 \%$ de ácidos graxos, 4,7\% de metanol e $12,1 \mathrm{mg} / \mathrm{kg}$ de sódio. As dietas experimentais (Tabela 1) foram formuladas para proporcionar um ganho médio de $200 \mathrm{~g} /$ dia seguindo as exigências nutricionais do NRC (2007). $\mathrm{O}$ volumoso utilizado foi feno de aveia e o concentrado composto por milho moído e/ou glicerina bruta, farelo de soja, soja grão moída e mistura mineral.
A relação volumoso:concentrado foi de 25:75. A dieta total foi dividida em três tratos diários: 8h00, $11 \mathrm{~h} 00$ e 16h00.

A condição corporal foi utilizada como critério de abate. Três avaliadores experientes atribuíram os escores de condição aos animais. Os animais foram abatidos quando a média dos três avaliadores esteve entre 2,5 e 3,0, com intervalos de 0,5 (RUSSEL et al., 1969). No total, o período experimental foi de 82 dias, do início do confinamento até o último animal abatido. Anteriormente ao abate, os animais permaneceram em jejum de sólidos recebendo água $a d$ libitum por um período de 12 horas e depois foram pesados para determinação do peso corporal ao abate (PCA). O abate foi realizado no Laboratório de Carnes da Universidade Federal da Grande Dourados, de acordo com as normas do Regulamento da Inspeção Industrial e Sanitária de Produtos de Origem Animal - RIISPOA (BRASIL, 2000).

Tabela 1. Composição percentual e química das dietas

\begin{tabular}{|c|c|c|c|c|}
\hline \multirow{2}{*}{ Alimentos ( $\mathrm{g} / \mathrm{kg}$ da dieta) } & \multicolumn{4}{|c|}{ Glicerina Bruta $(\mathrm{g} / \mathrm{kg})$} \\
\hline & 0 & 25 & 50 & 75 \\
\hline Feno de aveia & 243,30 & 243,30 & 243,30 & 243,30 \\
\hline Farelo de soja & 110,60 & 110,60 & 110,60 & 110,60 \\
\hline Grão de soja & 44,20 & 44,20 & 44,20 & 44,20 \\
\hline Glicerina bruta & 0,00 & 25,00 & 50,00 & 75,00 \\
\hline Milho triturado & 586,20 & 561,20 & 536,20 & 511,20 \\
\hline Calcário calcítico & 11,10 & 11,10 & 11,10 & 11,10 \\
\hline Sal comum & 4,60 & 4,60 & 4,60 & 4,60 \\
\hline \multicolumn{5}{|l|}{ Composição } \\
\hline $\mathrm{MS}^{1}(\mathrm{~g} / \mathrm{kg} \mathrm{MS})$ & 878,90 & 883,40 & 892,10 & 892,80 \\
\hline $\mathrm{PB}^{2}(\mathrm{~g} / \mathrm{kg} \mathrm{MS})$ & 161,50 & 159,00 & 156,50 & 154,00 \\
\hline $\mathrm{EE}^{3}(\mathrm{~g} / \mathrm{kg} \mathrm{MS})$ & 34,10 & 47,20 & 52,60 & 68,30 \\
\hline $\mathrm{MM}^{4}(\mathrm{~g} / \mathrm{kg} \mathrm{MS})$ & 60,60 & 57,50 & 62,40 & 67,20 \\
\hline $\mathrm{FDN}^{5}(\mathrm{~g} / \mathrm{kg} \mathrm{MS})$ & 249,20 & 246,90 & 244,70 & 242,40 \\
\hline $\mathrm{FDA}^{6}(\mathrm{~g} / \mathrm{kg} \mathrm{MS})$ & 145,40 & 144,40 & 143,40 & 142,40 \\
\hline $\mathrm{NDT}^{7}(\mathrm{~g} / \mathrm{kg} \mathrm{MS})$ & 767,80 & 769,10 & 770,40 & 771,70 \\
\hline $\mathrm{EM}^{8}(\mathrm{Mcal} / \mathrm{kg} \mathrm{MS})$ & 11,96 & 11,98 & 12,00 & 12,02 \\
\hline
\end{tabular}

${ }^{1} \mathrm{MS}=$ matéria seca; $\mathrm{PB}^{2}=$ proteína bruta; $\mathrm{EE}^{3}=$ extrato etéreo; $\mathrm{MM}^{4}=$ matéria mineral; $\mathrm{FDN}^{5}=$ fibra em detergente neutro; $\mathrm{FDA}^{6}=$ fibra em detergente ácido; $\mathrm{NDT}^{7}=$ nutrientes digestíveis totais; $\mathrm{EM}^{8}=$ energia metabolizável. 
Posteriormente à esfola, os cordeiros foram eviscerados, sendo registrados os pesos dos não componentes da carcaça: componentes corporais (sangue, pele, pés, cabeça e órgãos reprodutivos); gordura interna; vísceras brancas (esôfago, rúmenretículo, omaso, abomaso, intestino delgado e intestino grosso); vísceras vermelhas (coração, fígado, vesícula biliar, pâncreas, baço, rins e bexiga). $\mathrm{O}$ trato digestório foi pesado cheio e vazo para determinação do peso corporal vazio (PCV).

Em seguida, as carcaças foram pesadas para obter o peso de carcaça quente (PCQ), e levadas para a câmara de refrigeração com ar forçado, onde permaneceram durante 24 horas a $4^{\circ} \mathrm{C}$. Após o período de resfriamento foi aferido o $\mathrm{pH}$ e a carcaça foi novamente pesada para obtenção do peso da carcaça fria (PCF). Os rendimentos de carcaça foram calculados como: rendimento de carcaça quente $(R C Q)=\left(\frac{P C Q}{P C A}\right) \times 100$; rendimento de carcaça fria $(R C F)=$ $\left(\frac{P C F}{P C A}\right) \times 100 ;$ rendimento verdadeiro $(R V)=\left(\frac{P C Q}{P C V}\right) \times 100$; perda de peso no resfriamento $\quad(P P R)=\left(\frac{P C Q-P C F}{P Q}\right) \times$ 100.

As carcaças foram seccionadas ao longo da linha média, obtendo-se duas meias carcaças. A meia carcaça esquerda foi separada em oito cortes: pescoço, paleta, pernil, costelas fixas, costelas flutuantes, lombo com vazio, baixo e rabo conforme técnica adaptada por Osório \& Osório (2005). A paleta e o pernil foram utilizados para a dissecação, onde os músculos Triceps brachii e Semimembranosus foram retirados e armazenados para posterior análise qualitativa. $\mathrm{O}$ procedimento de dissecação foi realizado no Laboratório de Análise de Produtos Agropecuários da UFGD segundo a metodologia descrita por Osório \& Osório (2005).
$\mathrm{Na}$ dissecação foram separados os seguintes componentes teciduais: gordura subcutânea (localizada imediatamente sob a pele), gordura intermuscular (localizada abaixo da fáscia profunda, associada aos músculos), músculo (musculatura do corte mecanicamente separada dos demais tecidos), osso (base óssea de cada corte livre de qualquer outro tecido) e outros (tecidos não identificados, compostos por tendões, glândulas, nervos e vasos sanguíneos).

$\mathrm{Na}$ meia carcaça direita foram mensuradas as seguintes medidas objetivas: comprimento interno e externo da carcaça, comprimento de pernil, largura de pernil, profundidade de pernil e profundidade de peito. A meia carcaça direita foi ainda seccionada entre a $12^{\mathrm{a}} \mathrm{e}$ $13^{\mathrm{a}}$ vértebras torácicas, efetuando em película plástica transparente o desenho da área de olho de lombo, estabelecendose a largura e a profundidade máxima para o cálculo da área de olho de lombo (AOL), como descrito por Silva Sobrinho (1999), a partir da seguinte fórmula: $A O L=\left(\frac{A}{2} \times \frac{B}{2}\right) \times \pi$, em que: $\mathrm{A}=$ largura e $\mathrm{B}=$ profundidade. A espessura de gordura de cobertura (EGC) foi mensurada com auxílio de um paquímetro digital.

As características qualitativas da paleta e do pernil foram analisadas no Laboratório de Análise de Produtos Agropecuários da UFGD. A cor da carne foi determinada 30 minutos após a realização de um corte transversal no músculo, para a exposição da mioglobina ao oxigênio, utilizando-se colorímetro digital CR-400 Konica Minolta, com o qual avaliou-se a luminosidade $\left(\mathrm{L}^{*}\right)$, intensidade de vermelho $\left(a^{*}\right)$ e intensidade de amarelo (b*). Após a avaliação da cor, retirou-se uma amostra de aproximadamente $2 \mathrm{~g}$ e a mesma foi submetida a um peso de $2,250 \mathrm{~kg}$ por 5 minutos para a determinação da capacidade de retenção de água (CRA), conforme descrito por Cañeque \& Sañudo (2000). 
Rev. Bras. Saúde Prod. Anim., Salvador, v.17, n.4, p.729-743 out./dez., 2016 http://www.rbspa.ufba.br ISSN 15199940

Para a análise de perda de peso por cozimento (PPC) as amostras de carne foram assadas em forno elétrico até atingirem $70^{\circ} \mathrm{C}$ no seu centro geométrico, monitorado com termômetro digital. Os pesos dos bifes antes e depois da cocção foram utilizados para os cálculos das perdas por cozimento. Após o resfriamento dos bifes assados, retiraramse cilindros com $1,3 \mathrm{~cm}$ de diâmetro no sentido longitudinal das fibras musculares, para determinar a força cisalhamento (FC) em texturômetro, acoplado à lâmina Warner Bratzler de 1,0 $\mathrm{mm}$ de espessura, conforme metodologia proposta por Osório et al. (1998).

Para a determinação da composição centesimal utilizou-se os métodos propostos pela AOAC (1995), método 31.1.02 para a determinação do teor de umidade, 31.1.08 para proteína bruta (PB), 31.4.02 para extrato etéreo (EE) e 31.1.04 para matéria mineral (MM).

As análises estatísticas foram realizadas com auxílio do programa computacional SAS 9.2. Antes de submeter as variáveis estudadas ao procedimento de análise de variância, realizou-se $\mathrm{o}$ estudo para verificar se as pressuposições de distribuição normal e de homocedasticidade dos dados foram atendidas, através dos testes de ShapiroWilk e Bartlett, respectivamente. Os dados que não apresentaram distribuição normal foram transformados com a utilização do procedimento Box-Cox. Para analisar os dados foi utilizado análise de variância, e quando significativos foram submetidos a análise de regressão a 5\% de significância.

\section{RESULTADOS E DISCUSSÃO}

Não houve efeito dos teores crescentes de glicerina bruta $(\mathrm{P}>0,05)$ sobre o peso e rendimento dos não componentes da carcaça (Tabela 2). Maior Júnior et al. (2008), relataram que animais que apresentam idade, peso inicial e ao abate próximos, podem ter crescimento semelhante dos órgãos, já que os mesmos tem seu desenvolvimento ligado ao tamanho do animal. Essa afirmação é reforçada pelos dados obtidos no presente estudo por meio das medidas biométricas, na qual não encontrou diferença significativa entre as características avaliadas (ORRICO JUNIOR et al., 2015).

Tabela 2. Peso e rendimento dos não componentes da carcaça de cordeiros Pantaneiros alimentados com glicerina bruta em substituição ao milho

\begin{tabular}{|c|c|c|c|c|c|c|c|}
\hline \multirow{2}{*}{ Item } & \multicolumn{4}{|c|}{ Glicerina bruta $(\mathrm{g} / \mathrm{kg})$} & \multirow{2}{*}{ EPM } & \multicolumn{2}{|c|}{$P$} \\
\hline & 0 & 25 & 50 & 75 & & $\mathrm{~L}$ & Q \\
\hline Componentes corporais ${ }^{1}(\mathrm{~kg})$ & 8,90 & 7,62 & 8,03 & 7,84 & 0,42 & 0,20 & 0,25 \\
\hline Gordura interna $^{2}(\mathrm{~kg})$ & 1,34 & 1,16 & 1,12 & 1,39 & 0,56 & 0,84 & 0,10 \\
\hline Vísceras brancas ${ }^{3}$ cheias $(\mathrm{kg})$ & 7,32 & 6,89 & 6,94 & 6,57 & 0,91 & 0,16 & 0,93 \\
\hline Vísceras brancas vazias (kg) & 2,82 & 2,68 & 2,73 & 2,78 & 0,53 & 0,88 & 0,43 \\
\hline Vísceras vermelhas ${ }^{4}(\mathrm{~kg})$ & 2,17 & 1,96 & 2,04 & 2,00 & 0,91 & 0,08 & 0,12 \\
\hline Componentes corporais $(\%)$ & 22,31 & 19,09 & 20,12 & 19,64 & 0,67 & 0,20 & 0,25 \\
\hline Gordura interna (\%) & 3,35 & 2,92 & 2,81 & 3,48 & 0,89 & 0,84 & 0,10 \\
\hline Vísceras brancas cheias (\%) & 19,21 & 19,42 & 19,09 & 17,96 & 1,34 & 0,22 & 0,37 \\
\hline Vísceras brancas vazias (\%) & 7,07 & 6,73 & 6,85 & 6,96 & 0,82 & 0,88 & 0,43 \\
\hline Vísceras vermelha (\%) & 5,44 & 4,90 & 5,11 & 5,01 & 1,45 & 0,08 & 0,12 \\
\hline
\end{tabular}

${ }^{1}$ Componentes corporais (sangue, pele, pés, cabeça e órgãos reprodutivos); ${ }^{2}$ Gordura interna; ${ }^{3}$ Vísceras brancas (esôfago, rúmen-retículo, omaso, abomaso, intestino delgado e intestino grosso); ${ }^{4}$ Vísceras vermelhas (coração, fígado, vesícula biliar, pâncreas, baço, rins e bexiga). 
Rev. Bras. Saúde Prod. Anim., Salvador, v.17, n.4, p.729-743 out./dez., 2016 http://www.rbspa.ufba.br ISSN 15199940

Em ruminantes a inclusão de glicerol na dieta pode alterar a produção de ácidos graxos de cadeia curta no rúmen, favorecendo a produção de propionato (KOZLOSKI, 2002; DROUILLARD, 2008). A redução da proporção de acetato:propionato pode favorecer a produção de glicose em detrimento da síntese de gordura no próprio tecido adiposo, a partir do acetato. Essa alteração pode reduzir a deposição de gordura interna e visceral, no entanto, não houve efeito da inclusão de glicerina bruta sobre a deposição de gordura interna.

Houve efeito quadrático $(\mathrm{P}=0,04)$ para o peso de carcaça quente, no entanto, não alterou o rendimento carcaça quente (Tabela 3). A massa é obtida após a mensuração da carcaça livre de pele, cabeça, patas e vísceras, podendo ser esse o motivo para que o maior peso de carcaça quente tenha sido encontrado nos animais do tratamento com 7,5\% de inclusão de glicerina, pois estes mesmos animais apresentaram menor peso de não componentes da carcaça.

$\mathrm{O}$ rendimento verdadeiro dos cordeiros neste estudo variou de $60,86 \%$ a $61,97 \%$. Em estudo realizado por Gomes et al. (2011), ao avaliarem níveis de inclusão de glicerina $(0,15$ e $30 \%$ de glicerina/ $\mathrm{kg}$ MS) na dieta de cordeiros Santa Inês, observaram valor médio para rendimento biológico de carcaça de 55,65\%.

A perda de peso por resfriamento foi similar $(\mathrm{P}=0,41)$ entre os tratamentos. Além disso, seguiu-se padronização do tempo para realização do abate, resfriamento das carcaças e o monitoramento da temperatura $\mathrm{da}$ câmara fria, pois, segundo Pinheiro et al. (2009), a maturidade do animal, cobertura de gordura, condições atmosféricas da câmara frigorífica e o tempo de armazenamento das carcaças são fatores que interferem na porcentagem de perdas de peso ao resfriamento.

Tabela 3. Características de carcaça de cordeiros Pantaneiros alimentados glicerina bruta em substituição ao milho

\begin{tabular}{|c|c|c|c|c|c|c|c|}
\hline \multirow{2}{*}{ Item } & \multicolumn{4}{|c|}{ Glicerina bruta $(\mathrm{g} / \mathrm{kg})$} & \multirow{2}{*}{ EPM } & \multicolumn{2}{|c|}{$\mathrm{P}$} \\
\hline & 0 & 25 & 50 & 75 & & $\mathrm{~L}$ & Q \\
\hline $\mathrm{PCA}^{1}(\mathrm{~kg})$ & 38,10 & 35,52 & 36,50 & 37,84 & 1,60 & 0,09 & 0,08 \\
\hline $\mathrm{PCQ}^{2}(\mathrm{~kg})$ & 18,97 & 17,88 & 17,97 & 19,28 & 1,13 & 0,05 & 0,04 \\
\hline $\mathrm{PCF}^{3}(\mathrm{~kg})$ & 18,34 & 17,34 & 17,37 & 18,47 & 1,15 & 0,09 & 0,07 \\
\hline $\mathrm{PPR}^{4}(\%)$ & 3,31 & 3,08 & 3,40 & 3,80 & 0,74 & 0,41 & 0,17 \\
\hline $\mathrm{RCQ}^{5}(\%)$ & 49,77 & 50,40 & 49,87 & 50,61 & 1,10 & 0,83 & 0,97 \\
\hline $\mathrm{RCF}^{6}(\%)$ & 48,12 & 48,85 & 48,24 & 48,48 & 1,10 & 0,57 & 0,59 \\
\hline $\mathrm{RV}^{7}(\%)$ & 61,60 & 61,97 & 60,86 & 61,69 & 1,09 & 0,58 & 0,64 \\
\hline $\mathrm{AOL}^{8}\left(\mathrm{~cm}^{2}\right)$ & 13,80 & 14,30 & 13,60 & 14,30 & 1,25 & 0,96 & 0,90 \\
\hline $\mathrm{EGC}^{9}(\mathrm{~mm})$ & 1,51 & 1,81 & 1,51 & 2,22 & 0,72 & 0,77 & 0,40 \\
\hline Comprimento externo $(\mathrm{cm})$ & 58,75 & 58,25 & 57,67 & 56,00 & 1,29 & 0,99 & 0,43 \\
\hline Comprimento interno $(\mathrm{cm})$ & 62,00 & 61,00 & 61,00 & 61,60 & 1,31 & 0,26 & 0,29 \\
\hline Comprimento de perna $(\mathrm{cm})$ & 40,83 & 40,67 & 40,17 & 40,50 & 1,32 & 0,64 & 0,73 \\
\hline Largura de perna $(\mathrm{cm})$ & 10,20 & 9,50 & 9,92 & 9,67 & 0,94 & 0,47 & 0,57 \\
\hline Profundidade de perna $(\mathrm{cm})$ & 14,60 & 14,42 & 14,42 & 13,83 & 0,92 & 0,89 & 0,58 \\
\hline Profundidade de peito $(\mathrm{cm})$ & 27,00 & 25,90 & 26,10 & 26,17 & 1,02 & 0,13 & 0,21 \\
\hline Índice de compacidade $(\mathrm{kg} / \mathrm{cm})$ & 0,65 & 0,60 & 0,63 & 0,63 & 0,24 & 0,24 & 0,28 \\
\hline
\end{tabular}


Sabe-se que a glicerina bruta é rapidamente convertida em propionato no rúmen, o que ocasiona uma diminuição na relação acetato:propionato, sendo possível considerar que a glicerina pode causar efeitos sobre depósitos de gordura corporal (GUNN et al., 2010b), considerando a síntese de gordura a partir do acetato. Porém, neste trabalho não houve efeito da inclusão de glicerina bruta para espessura da gordura de cobertura. Os valores médios obtidos para EGC variaram de 1,51 a $2,22 \mathrm{~mm}$, estando os mesmos dentro dos valores recomendados por Andrade et al. (2009), onde de 1 a $3 \mathrm{~mm}$ são considerados aceitáveis.

Como a região entre a $12^{\mathrm{a}}$ e $13^{\mathrm{a}}$ vertebra torácica apresenta maturidade tardia, a AOL é indicada para representar o índice mais confiável do desenvolvimento e tamanho do tecido muscular (HASHIMOTO et al., 2012). Houve uma variação entre 13,63 e $14,30 \mathrm{~cm}^{2}$ de $\mathrm{AOL}$, intervalo semelhante ao valor médio encontrado por Rego et al. (2015) $13,66 \mathrm{~cm}^{2}$, e superior ao encontrado por Hashimoto et al. (2012) e Lage et al. (2014).

Não houve efeito $(\mathrm{P}>0,05)$ dos teores de glicerina bruta sobre a morfometria das carcaças, podendo estar relacionado com a padronização dos animais ao abate em função da condição corporal (Tabela 3). Da mesma maneira, a inclusão de glicerina bruta não influenciou o peso e rendimento do pescoço, paleta, perna, costelas e lombo (Tabela 4). Sabe-se que existe uma forte relação entre o peso da carcaça e o peso dos cortes comerciais (OSÓRIO et al., 2012), entretanto, mesmo com a relação significativa entre a inclusão de glicerina e PCQ, o mesmo efeito não ocorreu com os pesos e rendimentos dos cortes.

Não houve efeito dos diferentes teores de glicerina bruta $(\mathrm{P}>0,05)$ sobre a composição tecidual da carcaça (Tabela 4), da paleta (Tabela 5) e do pernil (Tabela 6) dos cordeiros. Martins et al. (2011), avaliando o efeito da dieta em terminação de cordeiros, também não encontraram diferença para composição tecidual da paleta. Isso provavelmente se deve ao fato de que, tanto no presente estudo quanto no estudo realizado por esses autores, o critério de abate escolhido foi a condição corporal, visto que animais com similares condições corporais no momento do abate e, de mesmo grupamento genético, provavelmente apresentarão similaridade em sua composição tecidual (SILVA SOBRINHO et al, 2008).

Animais alimentados com maiores teores de GB na dieta podem apresentar menores perdas de exsudato muscular devido à capacidade do glicerol em reter água no músculo (LAGE et al., 2014), como foi relatado por Parker et al. (2007) ao avaliarem o efeito da inclusão de glicerol na dieta de bovinos de corte durante o período de transporte e observaram que o tratamento com glicerol resultou em uma hiper-hidratação do animal, o que posteriormente implica em carne de melhor qualidade. No entanto, não houve efeito dos teores crescentes de GB para a CRA dos músculos avaliados no presente estudo (Tabela 7).

Não houve efeito dos teores crescentes de GB na dieta para as características PPC e FC dos diferentes músculos avaliados (Tabela 7). Os valores de FC variaram de 3,00 a $4,08 \mathrm{~kg}$, a carne dos cordeiros Pantaneiros é considerada macia por ser inferior a $4,5 \mathrm{~kg}$ (DUCKETT, 2003). Os animais do presente estudo apresentavam uma distribuição uniforme de gordura subcutânea nas carcaças, sendo que a gordura subcutânea age como um isolante térmico, reduzindo os efeitos do encurtamento das fibras musculares pelo frio (SAÑUDO et al., 1996), demonstrando que abatendo os animais por condição corporal há uma padronização no produto final, independente do tratamento utilizado. 
Tabela 4. Composição regional e tecidual da carcaça de cordeiros Pantaneiros alimentados glicerina bruta em substituição ao milho

\begin{tabular}{|c|c|c|c|c|c|c|c|}
\hline \multirow{2}{*}{ Item } & \multicolumn{4}{|c|}{ Glicerina bruta $(\mathrm{g} / \mathrm{kg})$} & \multirow{2}{*}{ EPM } & \multicolumn{2}{|c|}{$\mathrm{P}$} \\
\hline & 0 & 25 & 50 & 75 & & $\mathrm{~L}$ & $\mathrm{Q}$ \\
\hline \multicolumn{8}{|l|}{ Composição regional } \\
\hline Pescoço (kg) & 0,81 & 0,84 & 0,81 & 0,82 & 0,27 & 0,83 & 0,81 \\
\hline Paleta $(\mathrm{kg})$ & 1,75 & 1,59 & 1,66 & 1,60 & 0,46 & 0,40 & 0,55 \\
\hline Perna (kg) & 2,74 & 2,70 & 2,67 & 2,65 & 0,50 & 0,79 & 0,92 \\
\hline Lombo (kg) & 1,15 & 1,16 & 1,11 & 1,16 & 0,34 & 0,63 & 0,63 \\
\hline Costelas (kg) & 2,28 & 2,18 & 2,11 & 2,15 & 0,59 & 0,49 & 0,61 \\
\hline Pescoço (\%) & 9,22 & 9,88 & 9,69 & 9,69 & 1,17 & 0,51 & 0,59 \\
\hline Paleta (\%) & 19,36 & 18,73 & 19,69 & 19,32 & 0,92 & 0,88 & 0,73 \\
\hline Perna (\%) & 30,95 & 31,87 & 31,72 & 31,38 & 0,94 & 0,10 & 0,13 \\
\hline Lombo (\%) & 13,74 & 12,92 & 13,18 & 13,79 & 1,11 & 0,23 & 0,19 \\
\hline Costelas $(\%)$ & 25,85 & 25,59 & 24,87 & 25,22 & 1,43 & 0,59 & 0,72 \\
\hline \multicolumn{8}{|l|}{ Composição tecidual } \\
\hline Músculo (kg) & 4,43 & 4,26 & 4,19 & 4,23 & 0,55 & 0,26 & 0,40 \\
\hline Gordura subcutânea (kg) & 0,87 & 0,74 & 0,83 & 0,92 & 0,45 & 0,29 & 0,19 \\
\hline Gordura intermuscular (kg) & 0,97 & 0,88 & 0,82 & 0,97 & 0,42 & 0,11 & 0,11 \\
\hline Gordura total (kg) & 1,84 & 1,62 & 1,65 & 1,89 & 0,53 & 0,08 & 0,06 \\
\hline Osso (kg) & 1,70 & 1,62 & 1,61 & 1,55 & 0,44 & 0,63 & 0,89 \\
\hline Outros (kg) & 0,16 & 0,14 & 0,15 & 0,13 & 0,17 & 0,63 & 0,83 \\
\hline Músculo (\%) & 50,28 & 50,67 & 49,87 & 50,53 & 2,34 & 0,95 & 0,95 \\
\hline Gordura subcutânea (\%) & 9,06 & 7,68 & 8,69 & 9,63 & 1,46 & 0,29 & 0,19 \\
\hline Gordura intermuscular (\%) & 10,11 & 9,19 & 8,52 & 10,07 & 1,35 & 0,11 & 0,11 \\
\hline Gordura total (\%) & 19,17 & 16,87 & 17,21 & 19,69 & 1,71 & 0,08 & 0,06 \\
\hline Osso (\%) & 17,71 & 16,89 & 16,79 & 16,20 & 1,42 & 0,63 & 0,89 \\
\hline Outros $(\%)$ & 1,63 & 1,41 & 1,57 & 1,40 & 0,54 & 0,63 & 0,83 \\
\hline
\end{tabular}

Os diferentes teores de GB na dieta dos cordeiros Pantaneiros não afetaram ( $\mathrm{P}>0,05)$ o $\mathrm{pH}$ da paleta e do pernil (Tabela 7). $\mathrm{O}$ valor médio de $\mathrm{pH}$ foi de 5,68 e está dentro da faixa considerada normal para a carne ovina que varia de 5,5 a 5,8 (SAÑUDO et al., 1992). O glicogênio muscular é o principal substrato metabólico responsável pelo acúmulo de ácido lático post mortem promovendo assim o declínio do pH (BONAGURIO et al., 2003; BONACINA et al., 2011), que quando adequado provoca a correta queda do $\mathrm{pH}$ durante o processo de resfriamento, podendo indicar que outros parâmetros qualitativos como CRA, PPC, FC e cor apresentarão resultados satisfatórios, pois estes são influenciados pelo pH (BOUTON et al., 1971). 
Rev. Bras. Saúde Prod. Anim., Salvador, v.17, n.4, p.729-743 out./dez., 2016 http://www.rbspa.ufba.br ISSN 15199940

Tabela 5. Composição tecidual da paleta de cordeiros Pantaneiros alimentados com glicerina bruta em substituição ao milho

\begin{tabular}{|c|c|c|c|c|c|c|c|}
\hline \multirow{2}{*}{ Item } & \multicolumn{4}{|c|}{ Glicerina bruta $(\mathrm{g} / \mathrm{kg})$} & \multirow{2}{*}{ EPM } & \multicolumn{2}{|c|}{$\mathrm{P}$} \\
\hline & 0 & 25 & 50 & 75 & & $\mathrm{~L}$ & Q \\
\hline Músculo (kg) & 0,89 & 0,87 & 0,86 & 0,86 & 0,31 & 0,76 & 0,87 \\
\hline Gordura subcutânea $(\mathrm{kg})$ & 0,27 & 0,19 & 0,23 & 0,20 & 0,32 & 0,42 & 0,54 \\
\hline Gordura intermuscular (kg) & 0,08 & 0,07 & 0,09 & 0,09 & 0,17 & 0,87 & 0,99 \\
\hline Gordura total $(\mathrm{kg})$ & 0,35 & 0,26 & 0,28 & 0,29 & 0,30 & 0,16 & 0,23 \\
\hline Osso $(\mathrm{kg})$ & 0,36 & 0,31 & 0,32 & 0,32 & 0,19 & 0,07 & 0,18 \\
\hline Outros (kg) & 0,09 & 0,10 & 0,08 & 0,09 & 0,16 & 0,65 & 0,72 \\
\hline Músculo:Gordura & 2,88 & 3,41 & 3,21 & 3,19 & 0,92 & 0,37 & 0,42 \\
\hline Músculo:Osso & 2,46 & 2,76 & 2,68 & 2,70 & 0,46 & 0,06 & 0,14 \\
\hline Músculo (\%) & 51,26 & 54,74 & 52,69 & 53,92 & 1,91 & 0,34 & 0,46 \\
\hline Gordura subcutânea (\%) & 15,23 & 11,97 & 13,77 & 12,52 & 2,25 & 0,51 & 0,63 \\
\hline Gordura intermuscular (\%) & 4,51 & 4,46 & 5,90 & 5,25 & 1,28 & 0,50 & 0,71 \\
\hline Gordura total (\%) & 19,73 & 16,43 & 17,28 & 17,77 & 2,01 & 0,21 & 0,26 \\
\hline Osso $(\%)$ & 20,97 & 19,93 & 19,71 & 19,97 & 1,34 & 0,27 & 0,38 \\
\hline Outros $(\%)$ & 5,34 & 6,04 & 4,69 & 5,68 & 1,22 & 0,80 & 0,82 \\
\hline
\end{tabular}

Tabela 6. Composição tecidual do pernil de cordeiros Pantaneiros alimentados com glicerina bruta em substituição ao milho

\begin{tabular}{|c|c|c|c|c|c|c|c|}
\hline \multirow{2}{*}{ Item } & \multicolumn{4}{|c|}{ Glicerina bruta $(\mathrm{g} / \mathrm{kg})$} & \multirow{2}{*}{ EPM } & \multicolumn{2}{|c|}{$\mathrm{P}$} \\
\hline & 0 & 25 & 50 & 75 & & $\mathrm{~L}$ & Q \\
\hline Músculo (kg) & 1,55 & 1,57 & 1,49 & 1,52 & 0,38 & 0,79 & 0,94 \\
\hline Gordura subcutânea (kg) & 0,19 & 0,19 & 0,18 & 0,21 & 0,24 & 0,73 & 0,58 \\
\hline Gordura intermuscular (kg) & 0,19 & 0,15 & 0,17 & 0,17 & 0,23 & 0,40 & 0,46 \\
\hline Gordura total $(\mathrm{kg})$ & 0,37 & 0,34 & 0,35 & 0,38 & 0,28 & 0,42 & 0,37 \\
\hline Osso (kg) & 0,57 & 0,57 & 0,58 & 0,53 & 0,26 & 0,54 & 0,40 \\
\hline Outros (kg) & 0,16 & 0,14 & 0,15 & 0,13 & 0,16 & 0,62 & 0,83 \\
\hline Músculo:Gordura & 4,44 & 4,72 & 4,32 & 4,16 & 0,92 & 0,70 & 0,53 \\
\hline Músculo:Osso & 2,74 & 2,83 & 2,58 & 2,86 & 0,52 & 0,45 & 0,38 \\
\hline Músculo (\%) & 57,26 & 57,74 & 56,50 & 57,89 & 1,72 & 0,74 & 0,71 \\
\hline Gordura subcutânea (\%) & 6,82 & 6,89 & 6,83 & 7,90 & 1,42 & 0,74 & 0,55 \\
\hline Gordura intermuscular (\%) & 6,86 & 5,61 & 6,38 & 6,41 & 1,41 & 0,43 & 0,44 \\
\hline Gordura total (\%) & 13,68 & 12,51 & 13,22 & 14,31 & 1,58 & 0,37 & 0,28 \\
\hline Osso (\%) & 20,94 & 20,55 & 22,02 & 20,29 & 1,19 & 0,30 & 0,26 \\
\hline Outros $(\%)$ & 5,81 & 5,04 & 5,72 & 5,18 & 1,08 & 0,70 & 0,81 \\
\hline
\end{tabular}


Rev. Bras. Saúde Prod. Anim., Salvador, v.17, n.4, p.729-743 out./dez., 2016 http://www.rbspa.ufba.br ISSN 15199940

Tabela 7. Características qualitativas da paleta e do pernil de cordeiros Pantaneiros alimentados com glicerina bruta em substituição ao milho

\begin{tabular}{|c|c|c|c|c|c|c|c|}
\hline \multirow{2}{*}{ Item } & \multicolumn{4}{|c|}{ Glicerina bruta $(\mathrm{g} / \mathrm{kg})$} & \multirow{2}{*}{ EPM } & \multicolumn{2}{|c|}{$\mathrm{P}$} \\
\hline & 0 & 25 & 50 & 75 & & $\mathrm{~L}$ & Q \\
\hline \multicolumn{8}{|l|}{ Paleta } \\
\hline $\mathrm{pH}$ & 5,79 & 5,73 & 5,80 & 5,75 & 0,27 & 0,68 & 0,75 \\
\hline $\mathrm{CRA}^{1}(\%)$ & 90,47 & 93,34 & 92,64 & 93,67 & 1,59 & 0,21 & 0,42 \\
\hline $\operatorname{PPC}^{2}(\%)$ & 27,91 & 26,11 & 25,73 & 23,95 & 1,90 & 0,62 & 0,99 \\
\hline $\mathrm{FC}^{3}(\mathrm{~kg})$ & 3,57 & 3,86 & 3,22 & 3,19 & 0,80 & 0,87 & 0,54 \\
\hline $\mathrm{L}^{*^{4}}$ & 42,16 & 44,52 & 41,84 & 44,16 & 1,67 & 0,83 & 0,99 \\
\hline$a^{* 5}$ & 22,55 & 22,43 & 22,80 & 22,63 & 1,10 & 0,90 & 0,96 \\
\hline$b^{* 6}$ & 7,00 & 7,47 & 7,29 & 6,85 & 0,88 & 0,23 & 0,17 \\
\hline \multicolumn{8}{|l|}{ Pernil } \\
\hline $\mathrm{pH}$ & 5,59 & 5,52 & 5,58 & 5,68 & 0,33 & 0,17 & 0,06 \\
\hline CRA $(\%)$ & 84,14 & 86,51 & 86,06 & 87,02 & 1,31 & 0,09 & 0,30 \\
\hline PPC (\%) & 27,93 & 25,80 & 28,60 & 27,80 & 1,91 & 0,74 & 0,65 \\
\hline $\mathrm{FC}(\mathrm{kg})$ & 3,00 & 3,38 & 3,39 & 4,08 & 0,95 & 0,88 & 0,67 \\
\hline $\mathrm{L}^{*}$ & 40,06 & 41,83 & 42,20 & 39,99 & 1,53 & 0,06 & 0,05 \\
\hline$a^{*}$ & 22,43 & 22,39 & 23,51 & 22,05 & 1,08 & 0,29 & 0,25 \\
\hline $\mathrm{b}^{* 7}$ & 5,18 & 6,10 & 6,62 & 5,53 & 0,79 & 0,002 & 0,002 \\
\hline
\end{tabular}

${ }^{1} \mathrm{CRA}=$ capacidade de retenção de água; ${ }^{2} \mathrm{PPC}=$ perda de peso por cozimento; ${ }^{3} \mathrm{FC}=$ força de cisalhamento; ${ }^{4} \mathrm{~L}^{*}=$ luminosidade; ${ }^{5} \mathrm{a}^{*}=$ intensidade de vermelho; ${ }^{6} \mathrm{~b}^{*}=$ intensidade de amarelo; ${ }^{7} \mathrm{Y}=$ $5,12( \pm 0,27)+0,64( \pm 0,18) X-0,07( \pm 0,02) X^{2}, R^{2}=0,42$.

A cor do músculo Triceps brachii não foi influenciada pelos teores de GB na dieta (Tabela 7). Para o músculo Semimembranosus não houve efeito $(\mathrm{P}>0,05)$ dos teores de GB para luminosidade e intensidade de vermelho. Para a intensidade de amarelo houve efeito quadrático $(\mathrm{P}=0,002)$. Um dos fatores que podem influenciar a intensidade de amarelo da carne é a gordura intramuscular, no entanto, não houve efeito para o teor de extrato etéreo do músculo Semimembranosus.

Um dos possíveis fatores para a falta de efeito na intensidade de vermelho é o $\mathrm{pH}$, onde carne com $\mathrm{pH}$ mais elevado tendem a apresentar coloração mais escura (LEDWARD et al., 1986). Outro fator é a idade e como foi relatado por Renerre (1990) ocorre um aumento da concentração de mioglobina conforme aumenta a idade do animal. No entanto, o pH não foi alterado pelas dietas experimentais e os animais do presente estudo foram abatidos com a mesma idade.

Não houve efeito $(\mathrm{P}>0,05)$ dos teores crescente de GB na dieta para as características de umidade, proteína bruta e matéria mineral da paleta e do pernil (Tabela 8). O teor de extrato etéreo da paleta apresentou efeito linear decrescente $(\mathrm{P}=0,0001)$. Apesar da evidência do aumento da síntese de propionato com a inclusão de glicerina, há contradições a está ideia, pois a glicerina na alimentação pode resultar em diminuição da deposição de gordura intramuscular (DOUILLARD, 2012) ou tendem a diminuição como foi observado por Elam et al. (2008). 
Rev. Bras. Saúde Prod. Anim., Salvador, v.17, n.4, p.729-743 out./dez., 2016 http://www.rbspa.ufba.br ISSN 15199940

Tabela 8. Composição centesimal da paleta e do pernil de cordeiros Pantaneiros alimentados com glicerina bruta em substituição ao milho

\begin{tabular}{|c|c|c|c|c|c|c|c|}
\hline \multirow{2}{*}{ Item } & \multicolumn{4}{|c|}{ Glicerina bruta $(\mathrm{g} / \mathrm{kg})$} & \multirow{2}{*}{ EPM } & \multicolumn{2}{|l|}{$P$} \\
\hline & 0 & 25 & 50 & 75 & & $\mathrm{~L}$ & $\mathrm{Q}$ \\
\hline \multicolumn{8}{|l|}{ Paleta } \\
\hline Umidade (\%) & 78,03 & 77,51 & 78,29 & 77,69 & 0,87 & 0,88 & 0,82 \\
\hline Proteína Bruta (\%) & 17,69 & 17,71 & 17,93 & 18,18 & 0,91 & 0,99 & 0,74 \\
\hline Extrato Etéreo ${ }^{1}(\%)$ & 6,34 & 5,08 & 5,30 & 4,40 & 0,81 & 0,0001 & 0,26 \\
\hline Matéria Mineral (\%) & 0,79 & 0,89 & 0,91 & 0,77 & 0,43 & 0,19 & 0,17 \\
\hline \multicolumn{8}{|l|}{ Pernil } \\
\hline Umidade (\%) & 79,24 & 77,25 & 78,26 & 77,39 & 1,01 & 0,15 & 0,34 \\
\hline Proteína Bruta (\%) & 16,94 & 18,65 & 18,42 & 18,97 & 1,07 & 0,06 & 0,22 \\
\hline Extrato Etéreo (\%) & 5,44 & 6,73 & 4,83 & 6,56 & 1,07 & 0,82 & 0,98 \\
\hline Matéria Mineral (\%) & 1,14 & 1,16 & 1,19 & 1,21 & 0,32 & 0,67 & 0,96 \\
\hline
\end{tabular}

Considerando que a GB é $20,31 \%$ mais barata que o milho, como demonstrado por Bottini Filho (2012), em muitas regiões, sua utilização é viável economicamente ao nível de 7,5\% na dieta em substituição ao milho, sem detrimento da qualidade da composição tecidual dos cortes avaliados e características qualitativas da carne.

\section{REFERÊNCIAS}

ANDRADE, M.B.; MACEDO, F.A.F.; JOBIM, C.C.; LOMBARDI, L.; MACEDO, F.G.; GASPARINO, E. Características da carcaça e da carne de cordeiros terminados com dietas contendo diferentes proporções na silagem de grãos de milho. Acta Scientiarum. Animal Sciences, v.31, n.2, p.183-189, 2009.

ARAÚJO, F.E.; SILVA FILHO, A.S.; MOUSQUER, C.J.; OLIVEIRA, M.A.; MEXIA, A.A.; GERON, L.J.V.

Características qualitativas de carcaças de cordeiros mestiços Santa Inês X Pantaneiro terminados em pastagem recebendo suplementação. Revista Brasileira de Higiene e Sanidade Animal, v.8, n.2, p.263-278, 2014.

ASSOCIATION OF OFFICIAL ANALYTICAL CHEMISTS - AOAC. Official Methods of Analysis.

Washington, DC, 1995.

BONACINA, M.S.; OSÓRIO, M.T.M.; OSÓRIO, J.C.S.; CORRÊA, G.F.;

HASHIMOTO, J.H. Influência do sexo e do sistema de terminação de cordeiros Texel $\times$ Corriedale na qualidade da carcaça e da carne.

Revista Brasileira de Zootecnia, v.40, n.6, p.1242-1249, 2011.

BONAGURIO, S.; PÉREZ, J.R.O.; GARCIA, I.F.F.; BRESSAN, M.C.; LEMOS, A.L.S.C. Qualidade da carne de cordeiros Santa Inês puros e mestiços com Texel abatidos com diferentes pesos. Revista Brasileira de Zootecnia, v.32, n.6, p.1981-1991, 2003. (Supl. 2).

BOTTINI FILHO, F.D.E. Glicerina bruta na alimentação de cordeiros Pantaneiros confinados. 2012. 34p. 
Rev. Bras. Saúde Prod. Anim., Salvador, v.17, n.4, p.729-743 out./dez., 2016 http://www.rbspa.ufba.br ISSN 15199940

Dissertação (Mestrado em Zootecnia) Universidade Federal da Grande Dourados, Dourados.

BOUTON, P.E.; HARRIS, P.V.; SHORTHOSE, W.R. Effect of ultimate $\mathrm{pH}$ upon the water-holding capacity and tenderness of mutton. Journal of Food Science, v.36, p.435-439, 1971.

BRASIL. MINISTÉRIO DA AGRICULTURA, PECUÁRIA E ABASTECIMENTO. Instrução Normativa $\mathrm{n}^{\mathrm{o}} .3$, de 07 de janeiro de 2000. Regulamento técnico de métodos de insensibilização para 0 abate humanitário de animais de açougue. S.D.A./M.A.A. Diário Oficial da União, Brasília, 2000. p.14-16.

CAMILO, F.R.; VARGAS JUNIOR, F.M.; RICARDO, H.A.; FERNANDES, A.R.M.; SENO, L.O.; OSÓRIO, J.C.S.; SOUZA, M.R.; MOBIGLIA, A.M. The intake of thermally processed soybean reduces the feedlot period of lambs independently of roughage to concentrate ratio. Journal of Animal Science, v.93, p.3084-3090, 2015.

CAÑEQUE, V.; SAÑUDO, C.

Metodologia para el estúdio de la calidad de la canal y de la carne em ruminantes. Madrid: INIA, 2000.

CHI, Z.; PYLE, D.; WEN, Z.; FREAR, C.; CHEN, S. A laboratory study of producing docosahexaenoic acid from biodiesel-waste glycerol by microalgal fermentation. Process Biochemistry, v.42, p.1537-1545, 2007.

CRISPIM, B.A.; GRISOLIA, A.B.; SENO, L.O.; EGITO, A.A.; VARGAS JUNIOR, F.M.; SOUZA, M.R. Genetic diversity of locally adapted sheep from Pantanal region of Mato Grosso do Sul. Genetics and Molecular Research, v.12, n.4, p.5458-5466, 2013.
DROUILLARD, J.S. Glycerin as a feed for ruminants: using glycerin in highconcentrate diets. Journal of Dairy Science, v.86, p.392, 2008. (E-Suppl.2).

DROUILLARD, J.S. Utilization of crude glycerin in beef cattle. In: MAKKAR, H.P.S. (Ed.) Biofuel coproducts as livestock feed: opportunities and challenges Rome: Food and agriculture organization of the United Nation, 2012. p. 155-161.

\section{DUCKETT, S.K. Factors affecting} the palatability of lamb meat. 2003. Available in: $<$ http://www.ansci.wisc.edu/extensionnew\%20copy/sheep/wisline_03/sducke tt.pdf $>$

ELAM, N.A.; ENG, K.S.; BECHTEL, B.; HARRIS, J.M.; CROCKER, R. Glycerol from biodiesel production: Considerations for feedlot steers. In: SOUTHWEST NUTRITION CONFERENCE, 21., 2008, Tempe AZ. Proceedings... Tempe: University of Arizona 2008. p.131

GOMES, M.A.B.; MORAES, G.V.; MATAVELI, M.; MACEDO, A.F.; CARNEIRO, T.C.; ROSSI, R.M. Performance and carcass characteristics of lambs fed on diets supplemented with glycerin from biodiesel production. Revista Brasileira de Zootecnia, v.40, n.10, p.2211-2219, 2011.

GUNN, P.J.; NEARY, M.K.; LEMENAGER, R.P.; LAKE, S.L. Effects of crude glycerin on performance and carcass characteristics of finishing wether lambs. Journal of Animal Science, v.88, p.1771-1776, 2010a. 
Rev. Bras. Saúde Prod. Anim., Salvador, v.17, n.4, p.729-743 out./dez., 2016 http://www.rbspa.ufba.br ISSN 15199940

GUNN, P.J.; SCHULTZ, A.F.; VAN

EMON, M.L.; NEARY, M.K.;

LEMENAGER, R.P.; RUSK, C.P.;

LAKE, S.L. Effects of elevated crude glycerin concentrations on feedlot performance, carcass characteristics, and serum metabolite and hormone concentrations in finishing ewe and wether lambs. The Professional Animal Scientist, v.26, p.298-306, 2010b.

HASHIMOTO, J.H.; OSÓRIO, J.C.S.; OSÓRIO, M.T.M.; BONACINA, M.S.; LEHMEN, R.I.; PEDROSO, C.E.S. Qualidade da carcaça, desenvolvimento regional e tecidual de cordeiros terminados em três sistemas. Revista Brasileira de Zootecnia, v.41, n.2, p.438-448, 2012.

\section{KOZLOSKI, G.V. Bioquímica dos}

Ruminantes. Santa Maria:

Universidade Federal de Santa Maria, 2002.

LAGE, J.F.; PAULINO, P.V.R.; PEREIRA, L.G.R.; DUARTE, M.S.; VALADARES FILHO, S.C.; OLIVEIRA, A.S.; SOUZA, N.K.P.; LIMA, J.C.M. Carcass characteristics of feedlot lambs fed crude glycerin contaminated with high concentrations of crude fat. Meat Science, v.96, p.108-113, 2014.

LEDWARD, D.A.; DICKINSON, R.F.; POWELL, V.H.; SHORTHOSE, W.R. The colour and colour stability of beef Longissimus dorsi and Semimembranosus muscles after effective electrical stimulation. Meat Science, v.16, p.245-265, 1986.

MAIOR JÚNIOR, R.J.S.; CARVALHO, F.F.R.; BATISTA, Â.M.V. Rendimento e características dos componentes não-carcaça de ovinos alimentados com rações baseadas em cana -de-açúcar e uréia.

Revista Brasileira de Saúde

Produção Animal [online], v.9, n.3, p.507-515, 2008.

MARTINS, L.S.; OSÓRIO, M.T.M.; OSÓRIO, J.C.S.; LEMES, J.S.; ESTEVES, R.G.; LEHMEN, R.I.; OLIVEIRA, L.V. Composição tecidual de cortes da carcaça de cordeiros suplementados com ração contendo óleo de arroz. PUBVET, v.5, ed. 150, art.1006, 2011.

MILLEN, D.D.; PACHECO, R.D.L.; ARRIGONI, M.D.B.; GALYEAN, M.L.; VASCONCELOS, J.T. A snapshot of management practices and nutritional recommendations used by feedlot nutritionists in Brazil. Journal of Animal Science, v.87, p.34273439, 2009.

MORA, N.H.A.P.; MACEDO, F.A.F.; MEXIA, A.A.; DIAS-SENEGALHE, F.B.; OLIVEIRA, E.Q.; RADIS, A.C. Características de carcaça de cordeiras Pantaneiras abatidas com diferentes espessuras de gordura subcutânea.

Arquivo Brasileiro de Medicina Veterinária e Zootecnia, v.67, n.1, p.290-298, 2015.

MOURA NETO, J.B.; PEREIRA, L.G.R.; CHIZZOTTI, M.L.; YAMAMOTO, S.Y.; ARAGÃO, A.S.L.; MASCIOLI, A.S.

Componentes constituintes e não constituintes da carcaça de cordeiros Santa Inês alimentados com farelo de manga em substituiçãoao milho.

Semina: Ciências Agrárias, v.35, n.1, p.437-448, 2014.

NATIONAL RESEARCH COUNCIL NRC. Nutrient Requirements of Small Ruminants. Washington, DC: National Academy Press, 2007. 
Rev. Bras. Saúde Prod. Anim., Salvador, v.17, n.4, p.729-743 out./dez., 2016 http://www.rbspa.ufba.br ISSN 15199940

ORRICO JÚNIOR, M.A.P.; BOTTINI, F.D.E.; OSÓRIO, J.C.S.; VARGAS JUNIOR, F.M.; ORRICO, A.C.A. Glicerina bruta na dieta de cordeiros confinados: desempenho, características de carcaça e viabilidade econômica.

Bioscience Journal, v.31, n.4, p.11521158, 2015.

OSÓRIO, J.C.S.; OSÓRIO, M.T.M.

Produção de carne ovina: técnicas de avaliação "in vivo" e na carcaça. 2.ed. Pelotas: UFPel, 2005.

OSÓRIO, J.C.S.; OSÓRIO, M.T.M.; FERREIRA, O.G.L.; VARGAS JUNIOR, F.M.; FERNANDES, A.R.M.; RICARDO, H.A.; ALVES, L.G.C.; ORRICO JUNIOR, M.A.P. Avaliação da carcaça de caprinos e ovinos. Pubvet, v.6, n.23, art.1403, 2012.

OSÓRIO, J.C.S.; OSÓRIO, M.T.M.; JARDIM, P.O.C. Métodos para avaliação da produção de carne ovina: in vivo, na carcaça e na carne. Pelotas: UFPel,1998.

PARKER, A.J.; DOBSON, G.P.; FITZPATRICK, L.A. Physiological and metabolic effects of prophylactic treatment with the osmolytes glycerol and betaine on Bos indicus steers during long duration transportation. Journal of Animal Science, v.85, p.2916-2923, 2007.

PINHEIRO, R.S.B.; JORGE, A.M.; SOUZA, H.B.A. Características da carcaça e dos não-componentes da carcaça de ovelhas de descarte abatidas em diferentes estágios fisiológicos.

Revista Brasileira de Zootecnia, v.38, n.7, p.1322-1328, 2009.

REGO, F.C.A.; FRANÇOZO, M.C.; LUDOVICO, A.; LIMA, L.D.; LOPES, F.G.; BELAN, L.; SANTOS, M.D.; ZUNDTT, M.; CUNHA FILHO,
L.F.C.C.; CONSTANTINO, C.

Desempenho, viabilidade econômica e características de carcaça de cordeiros alimentados em confinamento com rações contendo diferentes teores de glicerina bruta. Semina: Ciências Agrárias, v.36, n.5, p.3445-3454, 2015.

RENERRE, M. Review: factors involved in the discoloration of beef meat.

Journal Food Science Technology, v.25, p.613-630, 1990.

RICARDO, H.A.; FERNANDES, A.R.M.; MENDES, L.C.N.; OLIVEIRA, M.A.G.; PROTES, V.M.; SCATEMA, E.M.; ROÇA, R.O.; ATHAYDE, N.B.; GIRÃO, L.V.C.; ALVES, L.G.C.

Carcass traits and meat quality differences between a traditional and an intensive production model of market lambs in Brazil: Preliminary investigation. Small Ruminant

Research, v.130, p.141-145, 2015.

RUSSEL, A.J.F.; DONEY, J.M.; GUNN, R.G. Subjective assessment of body fat in live sheep. The Journal of Agricultural Science, v.72, p.451-454, 1969.

SAÑUDO, C.; SANTOLARIA, M.P.; MARIA, G.; OSORIO, M.; SIERRA, I. Influence of carcass weight on instrumental and sensory lamb meat quality in intensive production systems. Meat Science, v.42, p.195-202, 1996.

SAÑUDO, C.A.; DELFA, R.; CASAS, M. Influencia del genótipo en la calidad de la carne del ternasco de Aragón. In: JORNADAS CIENTÍFICAS DE LA SOCIEDADE ESPÃNOLA DE OVINOTECNIA Y CAPRINOTECNIA, 16., 1992, Pamploma. Anais... Pamploma: SEOC, 1992. p.473-479. 
Rev. Bras. Saúde Prod. Anim., Salvador, v.17, n.4, p.729-743 out./dez., 2016 http://www.rbspa.ufba.br

SILVA SOBRINHO, A.G. Body composition and characteristics of carcass from lambs of different genotypes and ages at slaughter. Report (Post Doctorate in Sheep Meat Production). Palmerston North: Massey University, 1999.

SILVA SOBRINHO, A.G.; SAÑUDO, C.; OSÓRIO, J.C.S.; ARRIBAS, M.M.C.; OSÓRIO, M.T.M. Produção de carne ovina. Jaboticabal: Funep, 2008.

VARGAS JUNIOR, F.M.; MARTINS, C.F.; PINTO, G.S.; FERREIRA, M.B.; RICARDO, H.A.; LEÃO, A.G.; FERNANDES, A.R.M.; TEIXEIRA, A. The effect of sex and genotype on growth performance, feed efficiency, and carcass traits of local sheep group Pantaneiro and Texel or Santa Inês crossbred finished on feedlot. Tropical Animal Health and Production, v.46, p.869-875, 2014.

VARGAS JUNIOR, F.M.; MARTINS, C.F.; SOUZA, C.C.S.; PINTO G.S.; PEREIRA, H.F.; CAMILO, F.R.; AZEVEDO JUNIOR, N.P. Avaliação biométrica de cordeiros Pantaneiros. Agrarian, v.4, n.11, p.60-65, 2011.

Data de recebimento: $21 / 03 / 2016$

Data de aprovação: 15/09/2016 